\title{
Local Admixtures for Stabilizing Laterites for Building Purposes
}

\author{
Olekwu Benjamin Elah ${ }^{\# 1}$ \\ ${ }^{\#}$ Associate Professor, Department of Building, Federal University of Technology, Minna, Nigeria
}

\begin{abstract}
This paper examined the performance characteristics of laterites stabilized with some local admixtures for building purposes. The laterites used in this work were grayish laterite and reddish brown laterite. The admixtures used were powdered locust bean pods (PLBP) gotten from the brownish fruit pods of the locust bean tree (Parkia Filicoidea); dye residue (DR) which is the by-product/residue of indigo dyeing, which is predominantly carried out in Hausa land of Northern Nigeria; rice hush ash (RHA); and the mixture of the three admixtures. The performance characteristics of stabilized laterites examined are drying shrinkage, moisture absorption and compressive strength. Results of the performance characteristics tests carried out show that powdered locust bean pods performs better for stabilizing laterites followed by the combined mixture of the three stabilizers. Reddish brown laterite has been found to perform better with the stabilizers for producing bricks for building purposes. 15\% PLBP, 20\% DR, $20 \%$ RHA and $20 \%$ combined mixture of PLBP, DR and RHA are recommended for stabilizing greyish laterite while 20\% PLBP, 20\% DR, 20\% RHA and $20 \%$ combined mixture of PLBP, DR and RHA are recommended for stabilizing reddish brown laterite.
\end{abstract}

Keywords - Building Purposes, Compressive Strength, Drying Shrinkage, Local Admixtures, Moisture Absorption, Stabilizing Laterites

\section{Introduction and Literature Review}

The search for locally available building and construction materials has been the focus of some researchers in recent times because the high cost of conventional construction materials has made the average and low income earners unable to afford houses of their own. It is on this premise that Government and other important organization are encouraging the use of indigenous materials which are cheaper and abundantly available. Thus, there is the need to study or research into locally available materials and seek ways of improving on their performance in use.

In northern Nigeria for instance, fine red soil, clayey laterite soil, and reddish brown laterites and the like are in common use, but from past experience, these on their own, due to low strength cannot withstand the harsh weather condition and other external factors that may militate against them. Thus it becomes necessary to improve their binding and resistant properties by use of materials which would also possibly improve or enhance their performance characteristics. Some of these binding materials may be in the form of cement, lime, bitumen or the like, while some are local admixtures such as powdered locust bean pods, dye reside, rice husk ash, powdered fruit pods of acacia tree, etc.
Reference [1] show that in most rural parts of Northern Nigeria, majority of residential houses are built with mud and the walls and domed-shaped roofs are usually rendered seasonally with suitable mud renders mixed with suitable admixtures to improve performance. Some of these local admixtures are 'katsi'(dye residue), 'makuba'(powdered locust bean pods), 'gabaruwa' (powdered fruit pods of acacia tree), etc. 'Katsi' has been tested to be a suitable rendering admixture in mud rendering for area with $500 \mathrm{~mm}$ to $1250 \mathrm{~mm}$ rainfall per annum and for effective performance , $20 \%$ to $30 \%$ katsi by weight of soil had been recommended for incorporation into renders containing at least $60 \%$ fine-ground soil particles [1]

Reference [2] also found that 'makuba' is a suitable rendering admixture in mud renders for areas with $500 \mathrm{~mm}$ to $1250 \mathrm{~mm}$ rainfall per annum and for effective performance, $20 \%$ ' $m a k u b a$ ' by weight of soil had been recommended for incorporation into mud renders containing inorganic clay of low plasticity and up to $75 \%$ fine- ground soil particles while $25 \%$ ' $m a k u b a$ ' is recommended for mud renders containing inorganic clay of low plasticity and up to $57 \%$ fine- ground soil particles.

Historical buildings most of which stand as monuments today, such as 'Masallacin Jumma 'a' (Friday Mosque in Zaria City - Nigeria; Gidan Benimister; the British Council Library; Gidan dan Hausa; Gidan Rumfa and Gidan Murphy all in Kano City - Nigeria, have external wall surfaces rendered with makuba-mud render. Katsi-mud renders have also been used to render the external wall surfaces of some historical buildings such as Gidan Makama in Kano Municipal, and the Emir of Daura's Palace in Katsina State [1], [2].

Reference [3] found RHA to be a pozzolanic material that could be used in soil stabilization. In their investigation on three different soils stabilized with different percentages of RHA, they found that the liquid limits of the three soils had been decreased by about $(11-18) \%$ with the addition of $9 \%$ RHA, while the plasticity index decreased by about (32 80) $\%$. The authors said treatment with RHA showed a general reduction in the maximum dry weight with increase in the RHA content to minimum values at 9\% RHA content. They also found that the optimum moisture content generally increased with increase in RHA content and that there was enormous increase in the unconfined compressive strength with increase in RHA content for the soil to its maximum at RHA between $(6-8)$ percent. 
Research carried out by Reference [4] where the soil was stabilized with different percentages of RHA and a small amount of cement shows that the increase in RHA content increases the optimum moisture content but decreases the maximum dry density. Also, the California bearing ratio value and unconfined compressive stress of the soil was considerably improved with RHA content and 10\% RHA content with $6 \%$ cement was recommended as optimum amount for practical purpose [4].

Another research carried out by Reference [5] on A-7-6 lateritic soil stabilized with $2-12 \%$ rice husk ash by weight of dry soil shows a general decrease in the maximum dry density and increase in optimum moisture content with increase in RHA content. It was also found that there was slight improvement in the California bearing ratio and unconfined compressive strength with increase in the RHA content. According to the reference, the peak unconfined compressive strength values were recorded at between $6-8 \%$ RHA, indicating a little potential of using 6-8\% RHA for strength improvement of the lateritic soil.

The focus of this paper is to assess the performance characteristics of powdered locust bean pods, dye reside, rice husk ash and the combined mixture of the three stabilizers used for stabilizing grayfish and reddish brown laterites for building purposes.

In this investigation, the performance characteristics of reddish brown and grayish laterite bricks made with PLBP, DR and RHA, and the combined mixture of the three as stabilizers in the laterites for building purposes were examined. The results of this research will enable local builders to know which of these admixture(s) is or are more appropriate for stabilizing laterites and at what percentage. They will also know which laterite performs better in terms of their characteristic performances.

\section{A. Locust Bean Pod (makuba in Hausa Language)}

The locust bean pod is the brownish fruit pods of the locust bean tree (Parkia Filicoidea) known as Dorawa in Hausa Language. The Dorawa tree grows commonly and abundantly in Hausa land. When the fruits are matured and ripe, they are harvested from the tree and the inner yellow flesh of the fruits called kalwa in Hausa Language are usually eaten by children particularly. The seeds are processed in some ways by women to make locust bean also called daddawa in Hausa Language and iru in Yoruba Language which is used as a spice in traditional cooking in many part of Nigeria.

The pod which is about $3.0 \mathrm{~cm}$ in diameter and between 25 $-35 \mathrm{~cm}$ long are dried then pounded into powder using pestle and mortar. The resulting powdered locust bean pod is what is used as local admixture.

\section{B. Local Dye Residue (Katsi in Hausa Language)}

The term katsi is the Hausa name used in referring to the by-product/residue of indigo dyeing, which is predominantly carried out in Hausa land. The dyeing process is carried out by first digging up a pit generally of $(2.0-2.5 \mathrm{~m})$ deep with a diameter of about $(0.5-0.8 \mathrm{~m})$ and cementing its inner as well as its upper edge circumference. Water is poured into the pit, and baba (bark of Oak tree) together with ashes from burnt wood is added to it. It is then stirred continuously, until a muddy mixture is formed. The stirring is repeated consecutively for two days, after which, the indigo known as shuni in Hausa Language is added to it. The resultant product is used for the dying of locally woven cotton, given it deep indigo blue colour. The quantity of shuni used depends on the required colour shade. After a period of time, the effectiveness of the dye begins to wear off, forming a solution called dagwalo in Hausa Language. The dagwalo is left to stand in the pit for two days after which the whole solution is removed from the pit, leaving behind a dense deposit at its base.

The deposit is scrapped and removed from the pit and left to dry out completely. Upon drying, dafara (the root of a vine plant) is placed underneath it and set on fire. This is allowed to burn until a whitish ash is formed. It is the resultant residue that is called katsi [6], [7].

\section{Rice Husk Ash (RHA)}

Rice is cultivated in many part of this country [8] and rice husk is therefore abundantly available. Rice husk is a waste material obtained from the threshing of rice and it constitutes about one-fifth of the weight of the harvested crop. However, some millions of tones are available in the rice mills; only a small amount of this is used as animal feed, fuel, glazing materials, poultry and livestock bedding. The remaining tone is largely burnt as a means of disposal, a process which pollutes the air and may cause serious lung diseases such as silicosis.

Reference [9] has indicated that the chemical constituents of rice husk and rice husk ash (RHA) make these materials useful in building construction. It is generally believed that when rice husk is burnt, the ash formed has high silica content together with a little carbon. If the burning conditions are suitable, say, between controlled temperatures of $450-800^{\circ} \mathrm{C}$, the structure of the silica is finally divided and amorphous in which condition it can undergo a chemical reaction with lime, to form a stable compound- calcium silicate. This compound has cementitious properties and the cement is usually referred to as RHA cement.

\section{Materials and Experimental Procedures}

\section{A. Materials}

The materials used in this work are grayish laterite, reddish brown laterite, PLBP, DR, and RHA. The reddish brown and grayish laterites were obtained from Hayin Mallam 
Bello in Kaduna, DR from Zaria and PLBP from Kura in Kano. The RHA was collected from a local mill at Karfi in Kura local Government Area of Kano State of Nigeria. The rice husk was sun dried and screened. The screened husk was placed and burnt in an open air. The ash obtained after the husk was burnt completely and was placed in a free air circulation environment to cool and later sieved through BS sieve $200(0.075 \mathrm{~mm})$. The portion of the ash passing this sieve was used.

\section{B. Experimental Procedures}

Laboratory tests were conducted on grayish laterite and reddish brown laterites with $0,10,15,20$, and 25, percent of PLBP, DR and RHA by weight of the laterite as stabilizers. The tests conducted were particle size analysis, Atterberg limits, dry density/moisture content, chemical analysis, drying shrinkage, moisture absorption and compressive strength. All the tests except the moisture absorption test were performed in accordance with the procedure described in Reference [10]. The test for moisture absorption was performed in accordance with specification in the Handbook by Reference [11].

In the absorption test, each sample (100mm cube) was weighed and then dried out until no further weight reduction was recorded. Then the simples were exposed to constant saturation for seven days, and weighed again. The absorption is the increase in weight of the wet sample as a percentage of the dry weight. The results were averaged from five samples.

In preparing the samples, PLBP, DR and RHA were properly mixed in each case with the laterites in a metal tray manually and some amount of water approximating to the liquid limit values was added and then mixed thoroughly and used for the various tests.

\section{Results and Discussions}

\section{A. Results of Particle Size Analysis}

The summary of soil composition for grayish laterite and reddish brown laterite are as shown in table 1 .

TABLE 1 Summary of Soil Composition

\begin{tabular}{|c|c|c|c|c|c|c|c|}
\hline Soil Type & $\begin{array}{c}\text { Clay/Silt } \\
\text { Composi } \\
\text { tion (\%) }\end{array}$ & \multicolumn{2}{|c|}{ Sand Composition (\%) } & \multicolumn{3}{|c|}{ Gravel Composition (\%) } \\
\cline { 4 - 7 } & 57.06 & $\begin{array}{c}\text { Mediu } \\
\mathrm{m}\end{array}$ & Coarse & Fine & Medium & Coarse \\
\hline $\begin{array}{c}\text { Grayish } \\
\text { Laterite }\end{array}$ & 7.28 & 16.92 & 13.16 & 5.58 & - & - \\
\hline $\begin{array}{c}\text { Reddish } \\
\text { Brown } \\
\text { Laterite }\end{array}$ & 79.18 & 5.60 & 9.68 & 4.14 & 1.40 & - & - \\
\hline
\end{tabular}

From table 1, it could be seen that grayish laterite is composed of $57.06 \%$ of clay/silt, $37.36 \%$ sand and $5.58 \%$ fine gravel while reddish brown laterite is $79.18 \%$ clay/silt, $19.14 \%$ sand and $1.40 \%$ fine gravel. Reddish brown laterite has a high percentage of clay/silt content but lower percentage of sand and fine gravel compared to grayish laterite.

\section{B. Atterberg Limits}

The results of Atterberg Limit test (Liquid Limit, Plastic Limit and Plasticity Index) are given in table 2.

TABLE 2 Results of Atterberg Limit Test

\begin{tabular}{|l|l|l|l|}
\hline Soil Type & $\begin{array}{l}\text { Liquid Limit } \\
(\%)\end{array}$ & $\begin{array}{l}\text { Plastic Limit } \\
(\%)\end{array}$ & $\begin{array}{l}\text { Plasticity Index } \\
(\%)\end{array}$ \\
\hline $\begin{array}{l}\text { Grayish } \\
\text { Laterite }\end{array}$ & 42.0 & 28.29 & 13.71 \\
\hline $\begin{array}{l}\text { Reddish Brown } \\
\text { Laterite }\end{array}$ & 49.0 & 35.09 & 13.91 \\
\hline
\end{tabular}

Table 2 gives the liquid limit and plastic limit of grayish laterite as $42.00 \%$ and $28.29 \%$ respectively and those of reddish brown laterite as $49.00 \%$ and $35.09 \%$ respectively. The plasticity indices of grayish laterite and reddish brown laterite are $13.71 \%$ and $13.91 \%$ respectively. Reddish brown laterite has slightly high values of both liquid limit and plastic limit compared with those of grayish laterite but with similar plasticity indices.

\section{Results of Density/Moisture Content Test}

The results of the density/moisture content test shows that grayish laterite has a maximum dry density (MDD) of $1.62 \mathrm{~g} / \mathrm{cm}^{3}$ and optimum moisture content (OMC) of $17.81 \%$ while reddish brown laterite has a maximum dry density (MDD) of $1.63 \mathrm{~g} / \mathrm{cm}^{3}$, and optimum moisture content (OMC) of $19.25 \%$. From the above results, it can be seen that reddish brown laterite has slightly higher maximum dry density and optimum moisture content compared to those of grayish laterite.

\section{Results of Chemical Analysis}

The results of the chemical analysis of PLBP, DR and RHA carried out by the National Geoscience Research Laboratory of the Nigerian Geological Survey Agency in Kaduna, Kaduna State to determine the oxide composition is presented in table 3.

TABLE 3 Results of Chemical Analysis of DR, RHA, and PLBP

\begin{tabular}{|c|c|c|c|}
\hline Oxides & DR & RHA & PLBP \\
\hline $\mathrm{SiO}_{2}$ & 36.70 & 70.00 & 5.20 \\
\hline $\mathrm{P}_{2} \mathrm{O}_{5}$ & 2.20 & 10.00 & 5.09 \\
\hline $\mathrm{SO}_{3}$ & 0.30 & 1.00 & 1.50 \\
\hline
\end{tabular}




\begin{tabular}{|c|c|c|c|}
\hline $\mathrm{CL}$ & - & 0.20 & 3.06 \\
\hline $\mathrm{Br}$ & - & 0.015 & - \\
\hline $\mathrm{K}_{2} \mathrm{O}$ & 4.10 & 8.48 & 45.60 \\
\hline $\mathrm{CaO}$ & 50.08 & 7.27 & 34.60 \\
\hline $\mathrm{MgO}$ & 0.89 & - & 0.41 \\
\hline $\mathrm{TiO}_{2}$ & 0.997 & 0.29 & 0.60 \\
\hline $\mathrm{MgO}$ & 0.24 & 0.424 & 0.02 \\
\hline $\mathrm{Fe}_{2} \mathrm{O}_{3}$ & 2.71 & 1.40 & 2.27 \\
\hline $\mathrm{CuO}$ & - & 0.011 & 0.085 \\
\hline $\mathrm{BaO}$ & 0.59 & 0.095 & 0.52 \\
\hline $\mathrm{ZnO}$ & 0.26 & 0.48 & - \\
\hline $\mathrm{Cr}_{2} \mathrm{O}_{3}$ & 0.01 & - & - \\
\hline $\mathrm{V}_{2} \mathrm{O}_{5}$ & 0.41 & 0.004 & - \\
\hline
\end{tabular}

Fig. 2 (Plotted from table 5 in appendix I) illustrates the variation of drying shrinkage of reddish brown laterite with stabilizer content.

\section{E. Drying Shrinkage Test}

The variation of drying shrinkage of grayish laterite with stabilizer content is illustrated in figure 1 (Plotted from table 4 in appendix I).

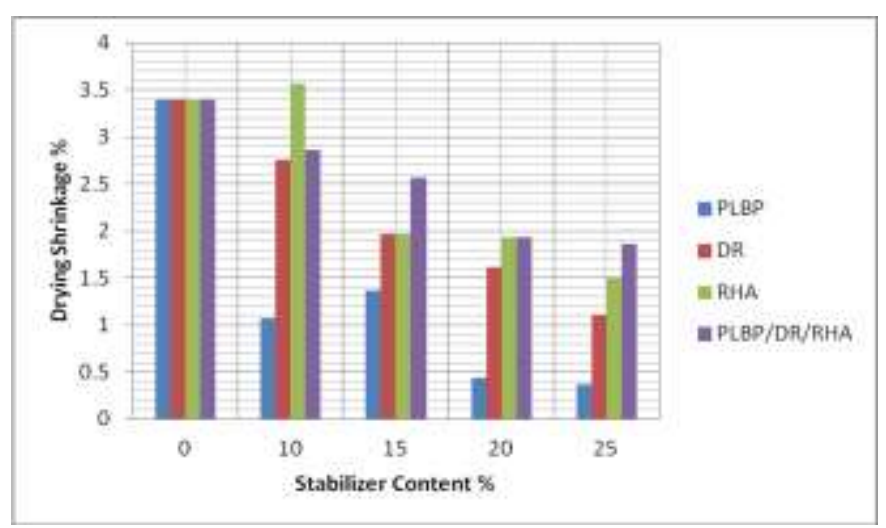

Fig. 1 variation of drying shrinkage of grayish laterite with stabilizer content

From Fig. 1 it could be seem that for all the stabilizers (PLBP, DR, RHA and PLBP/DR/RHA), dry shrinkage decreases as the stabilizer content increases. As shown on the graph, PLBP is more effective in reducing drying shrinkage followed by DR and then the combined mixture and RHA.

The reason why the use of PLBP reduces drying shrinkage more than DR and RHA can be explained from their chemical composition. PLBP has very low percentage of $\mathrm{SiO}_{2}$ (silicon oxide) $(5.20 \%)$ which is a cohesionless material like sand which offers little resistance to shrinkage compared to DR with $36.70 \%$ and RHA with $70.00 \%$ but higher percentage of $\mathrm{SO}_{3}$ (Sulphure trioxide) (1.50\%) that has binding property and is a component of gypsum used in the manufacture of cement compared to DR with $0.30 \%$ and RHA with $1.00 \%$.

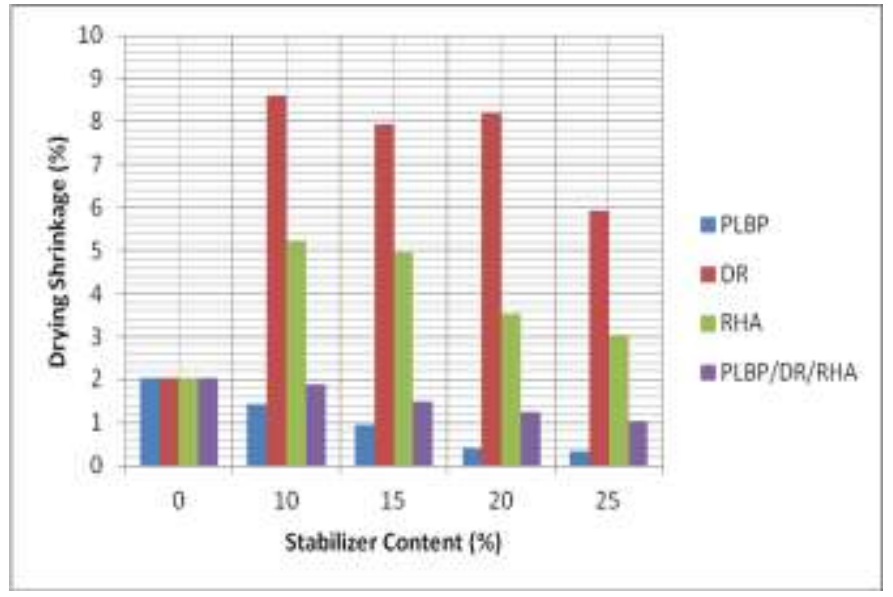

Fig. 2 shows that drying shrinkage of reddish brown laterite decreases with increase in stabilizer contents for PLBP and the combined mixture and is due to the influence of the binding properties of PLBP which tends to resist shrinkage. On the other hand the trend is different for DR and RHA where the shrinkage increases with increase in DR or RHA content. In fact while PLBP and the combined mixture reduce the drying shrinkage of reddish brown laterite, DR and RHA on the other hand increase it and this is because the high content of clay/silt $(79.18 \%)$ for reddish brown laterite as against $(57.06 \%)$ for grayish laterite makes the resulting mixture too high in fine particles which is liable to shrink.

\section{F. Moisture Absorption}

The variation of moisture absorption with stabilizers content is given in Fig. 3 (Plotted from table 6 in appendix I).

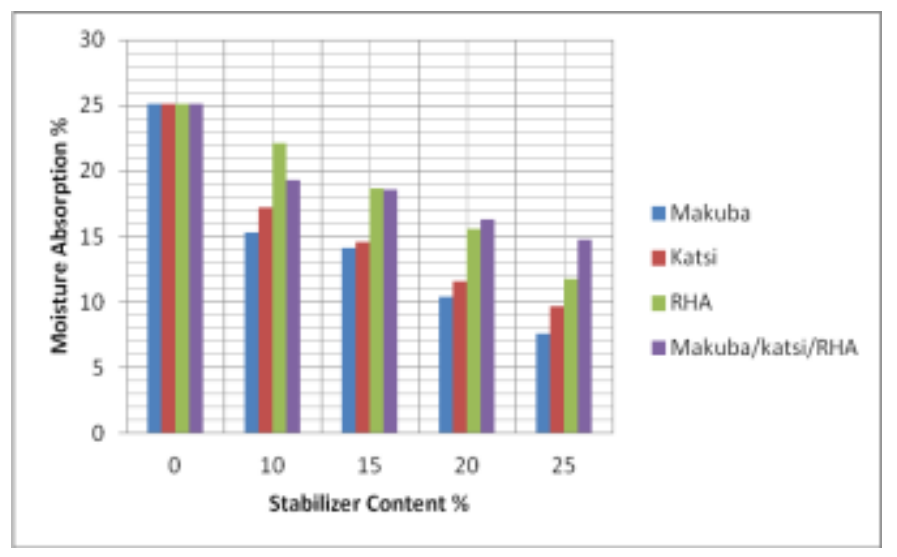

Fig. 3 variation of moisture absorption of grayish laterite with stabilizer content

From Fig. 3, it is seen that moisture absorption of grayish laterite decreases with increase in stabilizer content. PLBP is more effective in reducing moisture absorption followed by 


\section{International Journal of Engineering Trends and Technology (IJETT) - Volume 15 Number 5 - Sep 2014}

DR and then RHA and the combined mixture. Again this phenomenon can be explain from the fact that PLBP contains less cohesionless material which supports moisture absorption and more cohesive material which resists moisture absorption than DR and RHA.

The variation of moisture absorption with stabilizers content for reddish brown laterite is given in Fig. 4 (Plotted from table 7 in appendix I).

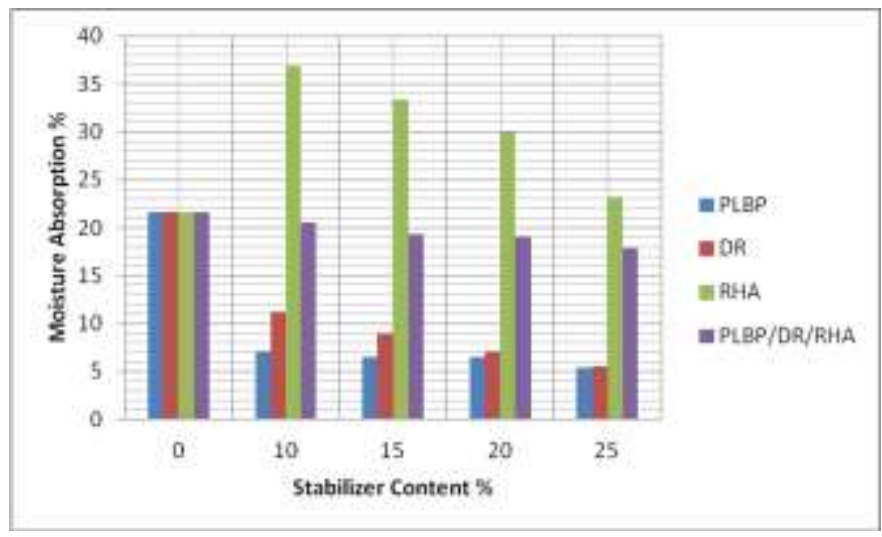

Fig. 4 variation of moisture absorption of reddish brown laterite with stabilizer content

From figure 4 , it is observed that moisture absorption of reddish brown laterite decreases with increase in PLBP, DR, and the combined mixture content. PLBP is more effective in reducing moisture absorption followed by $\mathrm{DR}$ and the combined mixture but RHA seems to rather increase moisture absorption of reddish brown laterite in line with the explanation given earlier for drying shrinkage.

\section{G. Compressive Strength}

The variation of compressive strength of grayish laterite with PLBP at the ages of 7, 14, 21, and 28 days is given in figure 5 (Plotted from table 8 in appendix I).

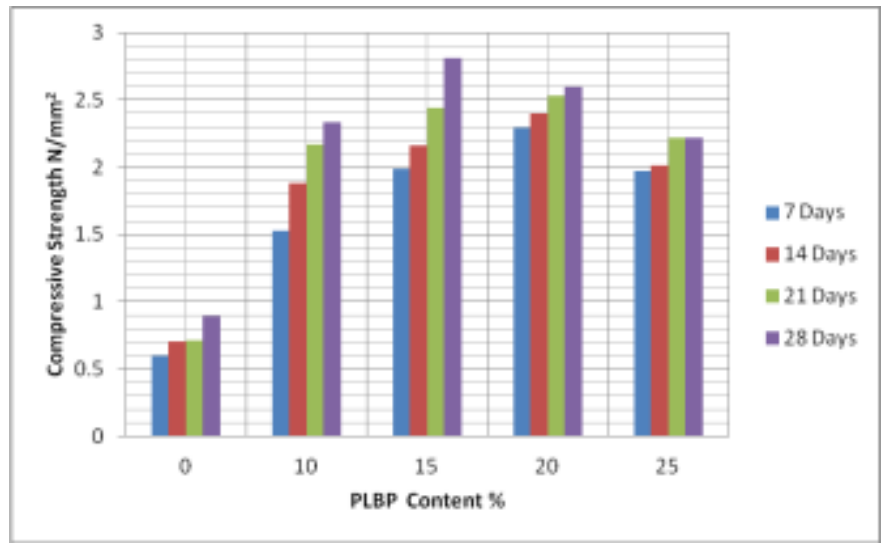

Fig. 5 variation of compressive strength of grayish laterite with PLBP content at the ages of $7,14,21$, and 28 days
From Fig. 5, it is seen that at the ages of 7, 14, 21 and 28 days the compressive strength increase with increase in PLBP content to a maximum value and then begins to reduce gradually. This trend shows that there is an optimum amount of PLBP above which the compressive strength starts reducing. This optimum PLBP content corresponding to the maximum compressive strength $\left(2.8 \mathrm{~N} / \mathrm{mm}^{2}\right)$ at the age of 28 days, from the graph is $15 \%$.

The variation of compressive strength of grayish laterite with DR at the ages of 7, 14, 21, and 28 days is given in Fig. 6 (Plotted from table 9 in appendix I).

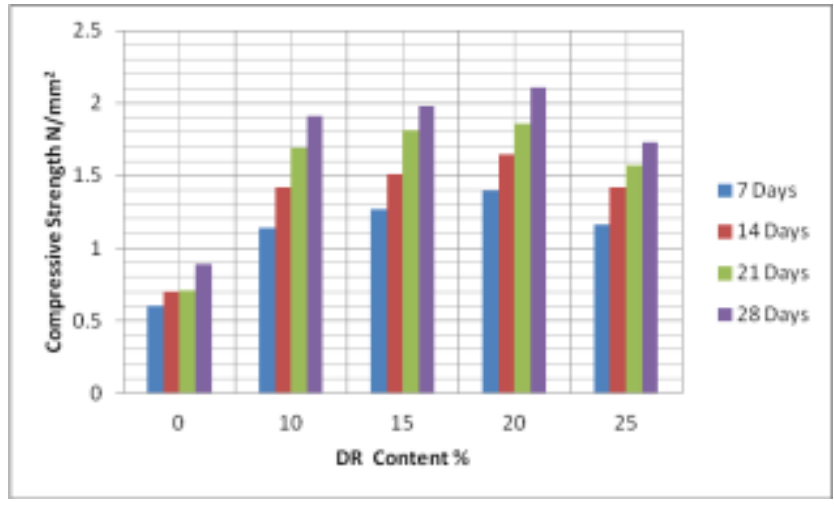

Fig. 6 variation of compressive strength of grayish laterite with DR content at the ages of $7,14,21$, and 28 days

From Fig. 6, it is seen that at the ages of 7, 14, 21 and 28 days the compressive strength increase with increase in DR content to a maximum value and then begins to reduce gradually. This trend again shows that there is an optimum amount of DR above which the compressive strength starts reducing. The optimum DR content corresponding to the maximum compressive strength $\left(2.1 \mathrm{~N} / \mathrm{mm}^{2}\right)$ at the age of 28 days, from the graph is $20 \%$.

The variation of compressive strength of grayish laterite with PLBP at the ages of 7, 14, 21, and 28 days is given in Fig. 7 (Plotted from table 10 in appendix I).

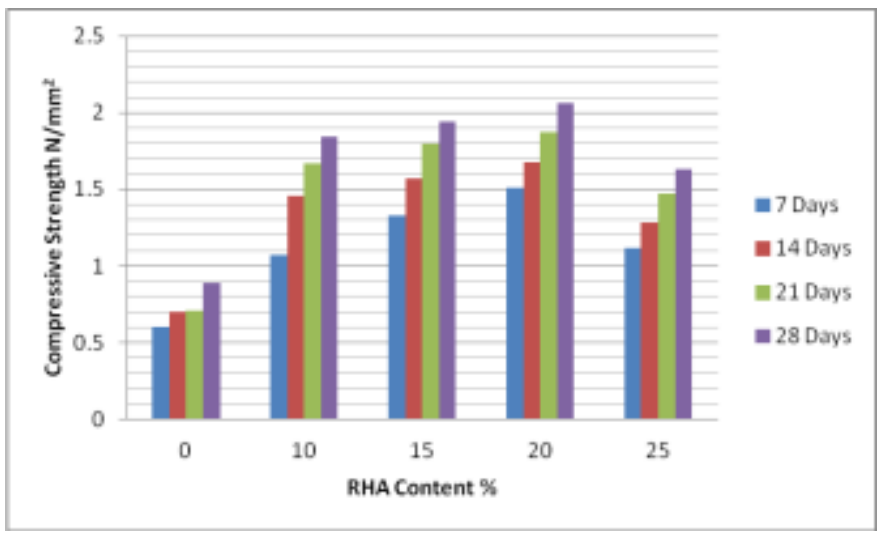

Fig. 7 variation of compressive strength of grayish laterite with RHA content at the ages of $7,14,21$, and 28 days 


\section{International Journal of Engineering Trends and Technology (IJETT) - Volume 15 Number 5 - Sep 2014}

From Fig. 7, it is seen that at the ages of 7, 14, 21 and 28 days the compressive strength increase with increase in RHA content to a maximum value and then begins to reduce gradually. This trend also shows that there is an optimum amount of RHA above which the compressive strength starts reducing. The optimum RHA content corresponding to the maximum compressive strength $\left(2.09 \mathrm{~N} / \mathrm{mm}^{2}\right)$ at the age of 28 days, from the graph is $20 \%$.

The variation of compressive strength of reddish brown laterite with PLBP at the ages of 7, 14, 21, and 28 days is given in Fig. 8 (Plotted from table 11 in appendix I).

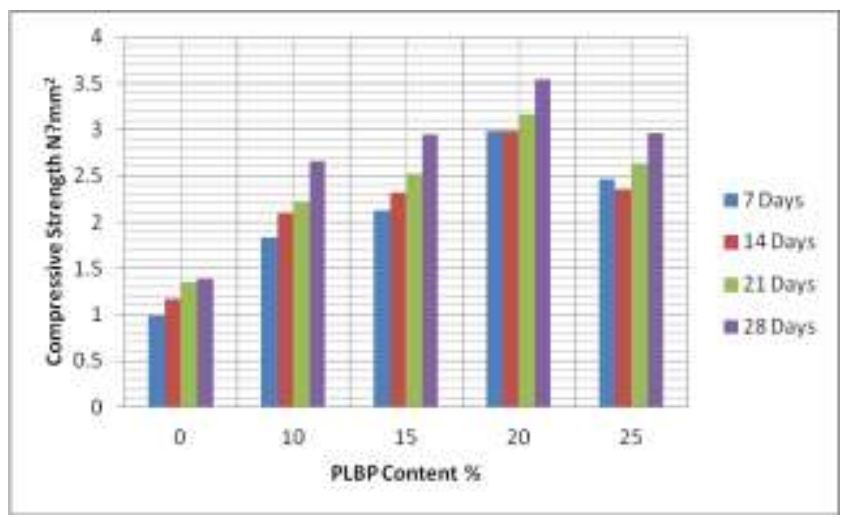

Fig. 8 variation of compressive strength of reddish brown laterite with PLBP content at the ages of $7,14,21$, and 28 days

From Fig. 8, it is seen that at the ages of 7, 14, 21 and 28 days the compressive strength increase with increase in PLBP content to a maximum value and then begins to reduce gradually. This trend shows that there is an optimum amount of PLBP above which the compressive strength starts reducing. This optimum PLBP content corresponding to the maximum compressive strength $\left(3.55 \mathrm{~N} / \mathrm{mm}^{2}\right)$ at the age of 28 days, from the graph is $20 \%$.

The variation of compressive strength of reddish brown laterite with DR content at the ages of 7, 14, 21, and 28 days is given in Fig. 9 (Plotted from table 12 in appendix I).

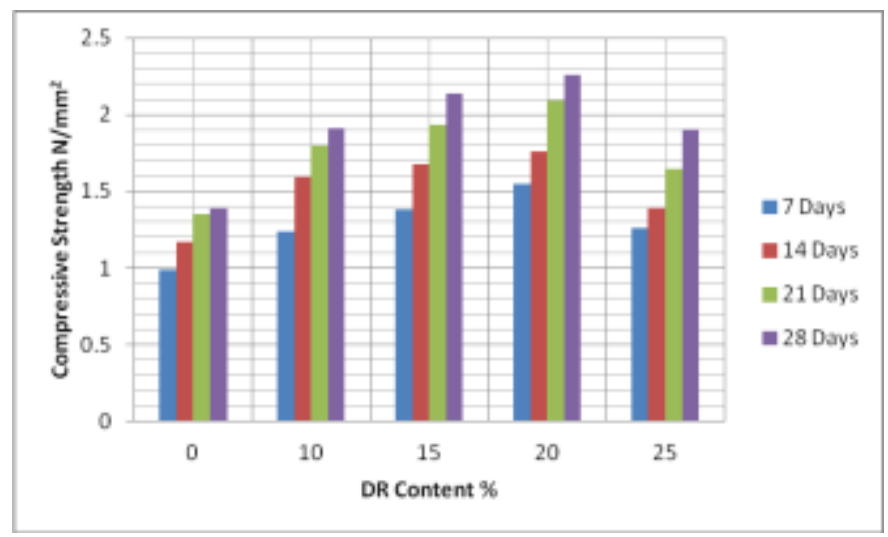

Fig. 9 variation of compressive strength of reddish brown laterite with DR content at the ages of $7,14,21$, and 28 days
From Fig. 9, it is seen that at the ages of 7, 14, 21 and 28 days the compressive strength increase with increase in DR content to a maximum value and then begins to reduce gradually. This trend again shows that there is an optimum amount of DR above which the compressive strength starts reducing. The optimum DR content corresponding to the maximum compressive strength $\left(2.29 \mathrm{~N} / \mathrm{mm}^{2}\right)$ at the age of 28 days, from the graph is $20 \%$.

The variation of compressive strength of reddish brown laterite with RHA at the ages of $7,14,21$, and 28 days is given in Fig. 10 (Plotted from table 13 in appendix I).

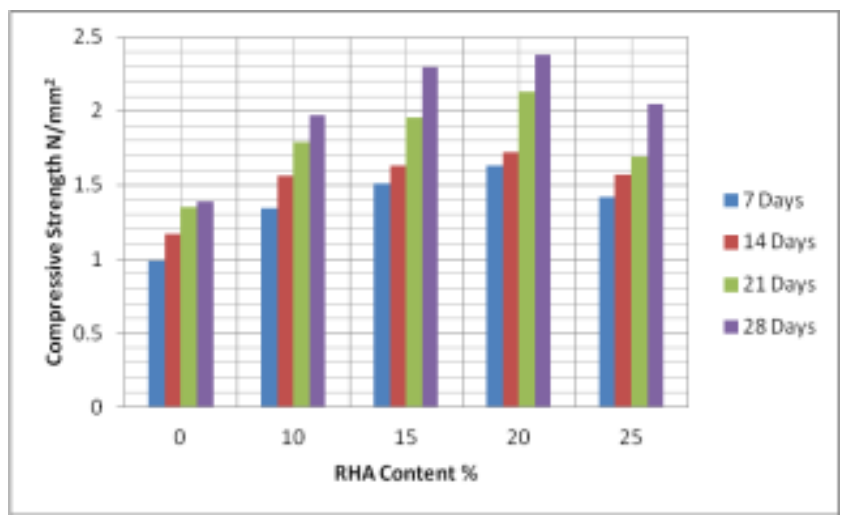

Fig. 10 variation of compressive strength of reddish brown laterite with RHA content at the ages of $7,14,21$, and 28 days

From Fig. 10, it is seen that at the ages of 7, 14, 21 and 28 days the compressive strength increase with increase in RHA content to a maximum value and then begins to reduce gradually. This trend also shows that there is an optimum amount of RHA above which the compressive strength starts reducing. The optimum RHA content corresponding to the maximum compressive strength $\left(2.40 \mathrm{~N} / \mathrm{mm}^{2}\right)$ at the age of 28 days, from the graph is $20 \%$.

The variation of compressive strength of grayish laterite with PLBP/DR/R at the ages of 7, 14, 21, and 28 days is given in Fig. 11 (Plotted from table 14 in appendix I).

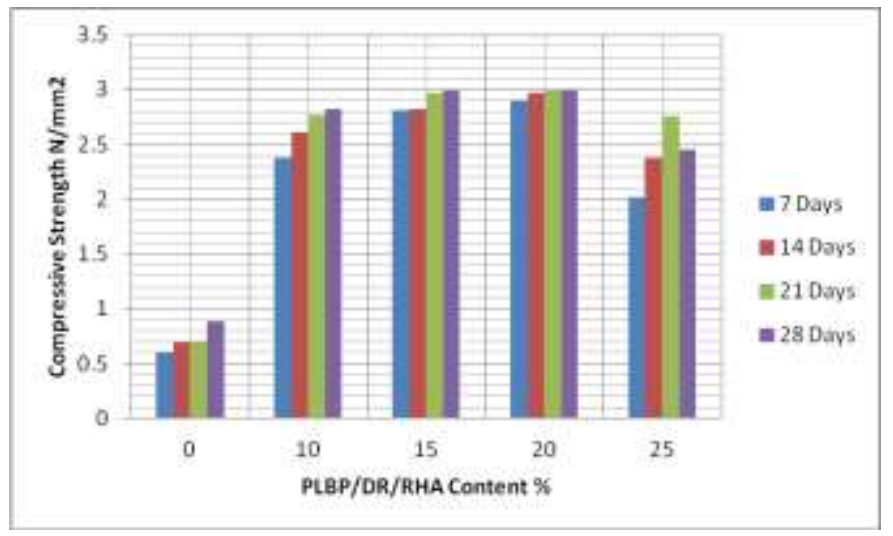

Fig. 11 variation of compressive strength of grayish laterite with PLBP/DR/RHA content at the ages of 7, 14, 21, and 28 days 
From Fig. 11, at the ages of 7, 14, 21 and 28 days the compressive strength increase with increase in RHA content to a maximum value and then begins to reduce gradually. The optimum PLBP/DR/RHA content corresponding to the maximum compressive strength $\left(3.05 \mathrm{~N} / \mathrm{mm}^{2}\right)$ at the age of 28 days, from the graph is $20 \%$.

The variation of compressive strength of reddish brown laterite with PLBP/DR/RHA content at the ages of 7, 14, 21, and 28 days is given in Fig. 12 (Plotted from table 15 in appendix I).

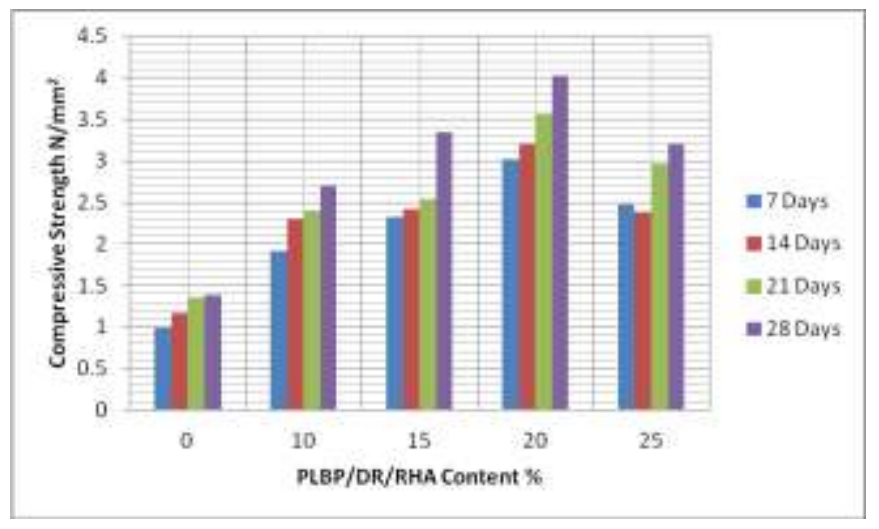

Fig. 12 variation of compressive strength of reddish brown laterite with PLBP/DR/RHA content at the ages of 7, 14, 21, and 28 days

From Fig. 12, at the ages of 7, 14, 21 and 28 days the compressive strength increase with increase in PLBP/DR/RHA content to a maximum value and then begins to reduce gradually. The optimum PLBP/DR/RHA content corresponding to the maximum compressive strength $\left(4.02 \mathrm{~N} / \mathrm{mm}^{2}\right)$ at the age of 28 days, from the graph is $20 \%$.

\section{Conclusion and Recommendation}

\section{A. Conclusion}

Base on the results of the performance tests carried out and in line with the aims and objectives of this project, the following conclusions are drawn;

- It has been established that for grayish laterite, powdered locust bean pods (PLBP) is more effective in reducing drying shrinkage followed by Dye residue (DR) and then rice husk ash (RHA). However, for reddish brown laterite, while PLBP reduces the drying shrinkage, DR and RHA on the other hand increase it.

- It was found that, for grayish laterite, PLBP is more effective in reducing moisture absorption followed by DR and then RHA. And in the case of reddish brown laterite, PLBP is also more effective in reducing moisture absorption followed by DR but RHA seems to rather increase moisture absorption of reddish brown laterite.

- For grayish laterite, the combined mixture of PLBP, DR and RHA produced bricks with the highest maximum compressive strength $\left(3.05 \mathrm{~N} / \mathrm{mm}^{2}\right)$ at the age of 28 days corresponding to an optimum stabilizer content of $20 \%$.
PLBP produced bricks with maximum compressive strength of $2.80 \mathrm{~N} / \mathrm{mm}^{2}$ at the age of 28 days corresponding to an optimum PLBP content of $15 \%$ while both DR and RHA produced bricks with maximum compressive strength of $2.1 \mathrm{~N} / \mathrm{mm}^{2}$ and $2.09 \mathrm{~N} / \mathrm{mm}^{2}$ respectively at the age of 28 days corresponding to an optimum DR or RHA content of $20 \%$ in each case.

- For reddish brown laterite, the combined mixture of PLBP, DR and RHA produced bricks with the highest compressive strength of $4.02 \mathrm{~N} / \mathrm{mm}^{2}$ at the age of 28 days corresponding to an optimum stabilizer content of $20 \%$. PLBP produced bricks with maximum compressive strength of $3.55 \mathrm{~N} / \mathrm{mm}^{2}$ at the age of 28 days corresponding to an optimum PLBP content of $20 \%$. Both DR and RHA produced bricks with maximum compressive strength of $2.29 \mathrm{~N} / \mathrm{mm}^{2}$ and $2.40 \mathrm{~N} / \mathrm{mm}^{2}$ respectively at the age of 28 days corresponding to an optimum DR or RHA content of $19 \%$ in each case.

- Finally, it is can be concluded that PLBP is more promising as a stabilizer followed by the combined mixture of PLBP, DR and RHA with respect to their performance characteristics as stabilizers in laterite. Reddish brown laterite has been found to be a more promising laterite for producing bricks for building purposes.

\section{B. Recommendation}

The following recommendations are proposed in order to derive benefits of PLBP, DR and RHA as a local soil stabilizing materials.

- $\quad 15 \%$ PLBP, $20 \%$ DR, 20\% RHA and 20\% combined mixture of PLBP, DR and RHA are recommended for stabilizing grayish laterite while 20\% PLBP, 20\% DR, 20\% RHA and $20 \%$ combined mixture of PLBP, DR and RHA are recommended for stabilizing reddish brown laterite

- PLBP is recommended as a better choice for stabilizing laterites.

- Reddish brown laterite is recommended as a better choice for producing bricks for building purposes.

\section{References}

[1] O. B. Ella, Effect of katsi (dye-residue) on the performance characteristics of mud renders, The Nigerian Academic Forum: A multidisciplinary Journal vol. 4 (2), pp. 48-54, 2003.

[2] O. B. Ella, Effect of 'makuba' on the performance characteristics of mud renders, The Nigerian Academic Forum: A multidisciplinary Journal vol. 8 (2), pp. 80-87, 2005.

[3] Mohammed Y. Fattah, Falah H. Rahil, Kawther Y. Al-Soudany, Improvement of clayey soil characteristics using rice husk ash, Journal of Civil Engineering and Urbanism, vol. 3(1), 12-18, 2013.

[4] A. Roy, Soil stabilization using rice husk ash and cement, International Journal of Civil Engineering Research ,vol.. 5 (1), 49-54, 2014.

[5] M. Alhassan, Potentials of rice husk ash for soil stabilization, $A U J$. T. Vol. 11(4), pp. 246-250, 2008.

[6] J.T. Johnny-Awharitoma, "The use of katsi (local dye residue) as local rendering admixture", B. Eng. Thesis, Bayero University, Kano - Nigeria, 1993.

[7] F. Adeniyi, "Laterized katsi - cement blocks for rural housing", postgraduate diploma thesis, Bayero University, Kano - Nigeria, 2002 . 
International Journal of Engineering Trends and Technology (IJETT) - Volume 15 Number 5 - Sep 2014

[8] L. A., Porteres, and D. A. Grist, Rice, $5^{\text {th }}$ ed., Longmans, 1980.

[9] D. J. Cook, R. P. Pama, and B. K. Paul, Rice husk ash-limecement mixes for use in masonry units, Building and Environment, Pergamon, Vol. 12, 281-288, 1977.

[10] British Standards, B.S. 1377, Methods for Testing Soils for Civil Engineering Purposes B.S. 1377, London, 1975.

[11] J. Norton, Building with Earth (a Handbook,) Intermediate Technology Development Group Limited, United Kingdom, 1986.

Appendix I: Tables

TABLE 4 Effects of Stabilizers on Drying Shrinkage of Grayish Laterite

\begin{tabular}{|c|c|c|c|c|}
\hline \multirow{2}{*}{$\begin{array}{c}\text { Stabilizer } \\
(\%)\end{array}$} & \multicolumn{4}{|c|}{ Drying Shrinkage (\%) } \\
\cline { 2 - 5 } & PLBP & DR & RHA & PLBP / DR /RHA \\
\hline 0 & 3.40 & 3.40 & 3.40 & 3.40 \\
\hline 10 & 1.07 & 2.75 & 3.57 & 2.86 \\
\hline 15 & 1.36 & 1.97 & 1.97 & 2.57 \\
\hline 20 & 0.43 & 1.61 & 1.93 & 1.93 \\
\hline 25 & 0.36 & 1.11 & 1.50 & 1.86 \\
\hline
\end{tabular}

TABLE 5 Effects of Stabilizers on Drying Shrinkage of Reddish Brown Laterite

\begin{tabular}{|c|c|c|c|c|}
\hline \multirow{2}{*}{$\begin{array}{l}\text { Stabilizer } \\
(\%)\end{array}$} & \multicolumn{4}{|c|}{ Brown Laterite } \\
\cline { 2 - 5 } & PLBP & DR & RHA & $\begin{array}{c}\text { PLBP / DR } \\
\text { /RHA }\end{array}$ \\
\hline 0 & 25.12 & 25.12 & 25.12 & 25.12 \\
\hline 10 & 15.28 & 17.24 & 22.10 & 19.31 \\
\hline 15 & 14.10 & 14.57 & 18.63 & 18.60 \\
\hline 20 & 10.40 & 11.57 & 15.59 & 16.32 \\
\hline 25 & 7.60 & 9.67 & 11.74 & 14.76 \\
\hline
\end{tabular}

TABLE 6 Effects of Stabilizers on Moisture Absorption of Grayish Laterite

\begin{tabular}{|c|c|c|c|c|}
\hline \multirow{2}{*}{$\begin{array}{l}\text { Stabilizer } \\
(\%)\end{array}$} & \multicolumn{4}{|c|}{ Laterite } \\
\cline { 2 - 5 } & PLBP & DR & RHA & PLBP / DR /RHA \\
\hline 0 & 25.12 & 25.12 & 25.12 & 25.12 \\
\hline 10 & 15.28 & 17.24 & 22.10 & 19.31 \\
\hline 15 & 14.10 & 14.57 & 18.63 & 18.60 \\
\hline 20 & 10.40 & 11.57 & 15.59 & 16.32 \\
\hline 25 & 7.60 & 9.67 & 11.74 & 14.76 \\
\hline
\end{tabular}

TABLE 7 Effects of Stabilizers on Moisture Absorption of Reddish Brown Laterite

\begin{tabular}{|c|c|c|c|c|}
\hline \multirow{2}{*}{$\begin{array}{l}\text { Stabilizer } \\
(\%)\end{array}$} & \multicolumn{4}{|c|}{ Moisture Absorption (\%) } \\
\cline { 2 - 5 } & PLBP & DR & RHA & PLBP/DR/RHA \\
\hline 0 & 21.64 & 21.64 & 21.64 & 21.64 \\
\hline 10 & 7.14 & 11.27 & 36.92 & 20.49 \\
\hline 15 & 6.53 & 8.97 & 33.39 & 19.36 \\
\hline 20 & 6.54 & 7.13 & 29.93 & 19.12 \\
\hline 25 & 5.39 & 5.57 & 23.25 & 17.83 \\
\hline
\end{tabular}

TABLE 8 Effects of PLBP and Curing Age on Compressive Strength of Grayish Laterite

\begin{tabular}{|c|c|c|c|c|}
\hline \multirow{2}{*}{$\begin{array}{l}\text { PLBP } \\
(\%)\end{array}$} & \multicolumn{4}{|c|}{ Compressive Strength $\left(\mathrm{N} / \mathrm{mm}^{2}\right)$} \\
\cline { 2 - 5 } & 7 Days & 14 Days & 21 Days & 28 Days \\
\hline 0 & 0.60 & 0.70 & 0.71 & 0.89 \\
\hline 10 & 1.53 & 1.88 & 2.17 & 2.33 \\
\hline 15 & 1.99 & 2.16 & 2.44 & 2.81 \\
\hline 20 & 2.29 & 2.40 & 2.53 & 2.60 \\
\hline 25 & 1.97 & 2.01 & 2.13 & 2.22 \\
\hline
\end{tabular}

TABLE 9 Effects of DR and Curing Age on Compressive Strength of Grayish Laterite

\begin{tabular}{|c|c|c|c|c|}
\hline \multirow{2}{*}{$\begin{array}{l}\text { DR } \\
(\%)\end{array}$} & \multicolumn{4}{|c|}{ Compressive Strength $\left(\mathrm{N} / \mathrm{mm}^{2}\right)$} \\
\cline { 2 - 5 } & 7 Days & 14 Days & 21 Days & 28 Days \\
\hline 0 & 0.60 & 0.70 & 0.71 & 0.89 \\
\hline 10 & 1.14 & 1.42 & 1.69 & 1.91 \\
\hline 15 & 1.27 & 1.51 & 1.81 & 1.98 \\
\hline 20 & 1.40 & 1.65 & 1.86 & 2.11 \\
\hline 25 & 1.16 & 1.42 & 1.57 & 1.73 \\
\hline
\end{tabular}

TABLE 10 Effects of RHA and Curing Age on Compressive Strength of Grayish Laterite

\begin{tabular}{|c|c|c|c|c|}
\hline \multirow{2}{*}{$\begin{array}{l}\text { RHA } \\
(\%)\end{array}$} & \multicolumn{4}{|c|}{ Compressive Strength $\left(\mathrm{N} / \mathrm{mm}^{2}\right)$} \\
\cline { 2 - 5 } & 7 Days & 14 Days & 21 Days & 28 Days \\
\hline 0 & 0.60 & 0.70 & 0.71 & 0.89 \\
\hline 10 & 1.07 & 1.46 & 1.67 & 1.84 \\
\hline 15 & 1.33 & 1.57 & 1.80 & 1.94 \\
\hline 20 & 1.51 & 1.68 & 1.87 & 2.06 \\
\hline 25 & 1.12 & 1.28 & 1.47 & 1.63 \\
\hline
\end{tabular}

TABLE 11 Effects of PLBP and Curing Age on Compressive Strength of Reddish Brown Laterite Grayish Laterite

\begin{tabular}{|c|c|c|c|c|}
\hline \multirow{2}{*}{$\begin{array}{l}\text { PLBP } \\
(\%)\end{array}$} & \multicolumn{4}{|c|}{ Compressive Strength $\left(\mathrm{N} / \mathrm{mm}^{2}\right)$} \\
\cline { 2 - 5 } & 7 Days & 14 Days & 21 Days & 28 Days \\
\hline 0 & 0.99 & 1.17 & 1.35 & 1.39 \\
\hline 10 & 1.84 & 2.10 & 2.22 & 2.66 \\
\hline 15 & 2.13 & 2.32 & 2.53 & 2.95 \\
\hline 20 & 2.98 & 2.98 & 3.17 & 3.54 \\
\hline 25 & 2.47 & 2.35 & 2.64 & 2.96 \\
\hline
\end{tabular}


TABLE 12 Effects of DR and Curing Age on Compressive Strength of Reddish Brown Laterite

\begin{tabular}{|c|c|c|c|c|}
\hline \multirow{2}{*}{$\begin{array}{l}\text { DR } \\
(\%)\end{array}$} & \multicolumn{4}{|c|}{ Compressive Strength $\left(\mathrm{N} / \mathrm{mm}^{2}\right)$} \\
\cline { 2 - 5 } & 7 Days & 14 Days & 21 Days & 28 Days \\
\hline 0 & 0.99 & 1.17 & 1.35 & 28 Days \\
\hline 10 & 1.24 & 1.59 & 1.80 & 1.39 \\
\hline 15 & 1.38 & 1.68 & 1.93 & 1.91 \\
\hline 20 & 1.55 & 1.76 & 2.09 & 2.14 \\
\hline 25 & 1.26 & 1.39 & 1.65 & 2.26 \\
\hline
\end{tabular}

Table 13 Effects of RHA and Curing Age on Compressive Strength of Reddish Brown Laterite

\begin{tabular}{|c|c|c|c|c|}
\hline \multirow{2}{*}{$\begin{array}{l}\text { RHA } \\
(\%)\end{array}$} & \multicolumn{4}{|c|}{ Compressive Strength $\left(\mathrm{N} / \mathrm{mm}^{2}\right)$} \\
\cline { 2 - 5 } & 7 Days & 14 Days & 21 Days & 28 Days \\
\hline 0 & 0.99 & 1.17 & 1.35 & 1.39 \\
\hline 10 & 1.34 & 1.56 & 1.79 & 1.97 \\
\hline 15 & 1.51 & 1.63 & 1.96 & 2.30 \\
\hline 20 & 1.63 & 1.72 & 2.13 & 2.38 \\
\hline 25 & 1.42 & 1.57 & 1.69 & 2.05 \\
\hline
\end{tabular}

Table 14 Effects of Combined mixture (PLBP/ DR /RHA) and Curing Age on Compressive Strength of Grayish Laterite

\begin{tabular}{|c|c|c|c|c|}
\hline \multirow{2}{*}{$\begin{array}{c}\text { (PLBP/DR/RHA }) \\
(\%)\end{array}$} & \multicolumn{5}{|c|}{ Compressive Strength $\left(\mathrm{N} / \mathrm{mm}^{2}\right)$} \\
\cline { 2 - 5 } & 7 Days & $\begin{array}{c}14 \\
\text { Days }\end{array}$ & 21 Days & $\begin{array}{l}28 \\
\text { Days }\end{array}$ \\
\hline 0 & 0.60 & 0.70 & 0.71 & 0.89 \\
\hline 10 & 2.38 & 2.61 & 2.77 & 2.82 \\
\hline 15 & 2.81 & 2.82 & 2.97 & 2.99 \\
\hline 20 & 2.90 & 2.97 & 2.99 & 3.00 \\
\hline 25 & 2.02 & 2.38 & 2.76 & 2.45 \\
\hline
\end{tabular}

Table 15 Effects of Combined mixture (PLBP/ DR /RHA) and Curing Age on Compressive Strength of Reddish Brown Laterite

\begin{tabular}{|c|c|c|c|c|}
\hline $\begin{array}{c}\text { (PLBP/DR/RHA }) \\
(\%)\end{array}$ & \multicolumn{4}{|c|}{ Compressive Strength $\left(\mathrm{N} / \mathrm{mm}^{2}\right)$} \\
\cline { 2 - 5 } & 7 Days & 14 Days & 21 Days & $\begin{array}{l}28 \\
\text { Days }\end{array}$ \\
\hline 0 & 0.99 & 1.17 & 1.35 & 1.39 \\
\hline 10 & 1.34 & 2.29 & 2.39 & 2.70 \\
\hline 15 & 1.51 & 2.42 & 2.54 & 3.35 \\
\hline 20 & 1.63 & 3.21 & 3.56 & 4.02 \\
\hline 25 & 1.42 & 2.38 & 2.97 & 3.21 \\
\hline
\end{tabular}

